Down's syndrome were significantly more sensitive to chickenpox infection than those from control subjects.

Chromosomal aberrations observed after infection were mainly chromosome breaks involving both chromatid and chromosome types. The present results showed that the difference between the observed and the expected values for breakage in one particular chromosome was not significant.

\section{REFERENCES AND NOTES}

1. Aula, P.: Virus-associated chromosome breaks. Amer. Acad. Sci. Ser. A. Biol. 89: 1 (1965).

2. Baumiller, R. C.: Virus induced point mutation. Nature, 214: 806 (1967)

3. Burdette, W. J., and Yoon, J. S.: Mutation, chromosomal aberrations and tumors in insects treated with oncogenic virus. Science, 155: 340 (1967).

4. German, J.: Chromosomal breakage syndromes. Birth Defect., 5: 117, (1969).

5. Higurashi, M., and Conen, P. E.: In vitro chromosomal radiosensitivity in pa tients and in carriers with non-Down's syndrome karyotypes. Pediat. Res., 6 : $514(1972)$.

6. Higurashi, M., Tamura, T., and Nakatake, T.: Cytogenetic observations in cultured lymphocytes from patients with Down's syndrome and measles. Pediat. Res., 7: 582 (1973).

7. Higurashi, M., and Conen, P. E.: In vitro chromosomal radiosensitivity in "Chromosomal breakage syndrome." Cancer, 32: 380 (1973).

8. Krivit, W., and Good, R. A.: Simultaneous occurrence of monogolism and leukemia. Report of nationwide survey. J. Dis. Childhood, 94: 289 (1957).

9. Miller, R. W., and Fraumeni, J. F., Jr.: Down's syndrome and neonatal leukemia Lancet, ii: 404 (1968).

10. Moorhead, P. S., Nowell, P. C., and Mellman, W. J., et al.: Chromosome preparations of leukocytes cultured from human peripheral blood. Exp. Cell Res., 20: 613 (1960)

11. Nichols, W. W., Levan, A., Hall, B., and Östergren, G.: Measles associated chromosome breakage. Preliminary communication. Hereditas, 48: 367 (1962).

12. Sasaki, M. S. and Tonomura, A.: Chromosomal radiosensitivity in Down's syndrome. Jap. J. Hum. Gent., 14: 81 (1969).

13. Schroeder, T. M., and Kurth, R.: Spontaneous chromosomal breakage and high incidence of leukemia in inherited disease. Blood, 37: 96 (1971)

14. Schunk, G. J., and Lehman, W. L.: Mongolism and congenital leukemia. J. Amer. Med. Ass., 155: 250 (1954).

15. Swift, M. R., and Herschhorn, K.: Fanconi's anemia inherited susceptibility to chronosome breakage in Various trissues. Ann. Intern. Med. 65:496 (1966).

16. Todaro, G. J., and Martin, G. M.: Increased susceptibility of Down's syndrome fibroblasts to transformation by SV 40. Proc. Soc. Exp. Biol. Med., 124: 1232 (1967).

17. We wish to thank Dr. J. M. Sturgess Department of Pathology, The Hospital for Sick Children, Toronto, Canada, for her advice on English expression.

18. Dr. M. Higurashi, attending cytogenetist, Department of Pediatrics, University of Tokyo, Japan.

19. This research was supported by grants from the Scientific Research

20. Requests for reprints should be addressed to: M. Higurashi, M.D., Department of Maternal and Child Health, School of Health Sciences, Faculty of Medicine, University of Tokyo, Hongo, Bunkyo-ku, Tokyo 113 (Japan).

21. Accepted for publication November 10, 1975.
Glucose

insulin

ketogenesis ketone bodies ketosis

\title{
Insulin, A Possible Regulator of Ketosis in Newborn and Suckling Rats
}

\author{
YU-YAN YEH(38) AND PAULUS ZEE
}

Laboratory of Nutrition and Metabolism, St. Jude Children's Research Hospital, Memphis, and Department of Physiology and Biophysics, University of Tennessee Center for the Health Sciences, Memphis, Tennessee, USA

Extract

A possible regulatory role of insulin in the development of ketosis in newborn and suckling rats was investigated. The average plasma concentration of total ketone bodies measured at birth was $0.414 \pm$ $0.037 \mu \mathrm{mol} / \mathrm{ml}$. Within $24 \mathrm{hr}$ after birth the level of ketones had increased to 4 times its initial value. The 3- to 4-fold increase in plasma ketones was maintained during the first 5 days of life but started to decline thereafter. Plasma insulin of newborn rats at birth $(62 \pm 8 \mu \mathrm{U} / \mathrm{ml})$ was comparable to that of fed adult rats $(85 \pm 10$ $\mu \mathrm{U} / \mathrm{ml})$. The levels decreased to $28 \mu \mathrm{U} / \mathrm{ml}$ on the first day of life and stayed low throughout the suckling period despite a tendency to increase at the time close to weaning. The capacities for ketone production in liver homogenates of suckling rats were inversely related to the levels of insulin. Administration of insulin (0.125 $\mathrm{mU} / \mathrm{g}$ body weight, im) and glucose $(1.75 \mathrm{mg} / \mathrm{g}$ body weight, ip) both suppressed plasma ketone bodies in suckling rats. Insulin administration increased plasma insulin but failed to decrease plasma glucose. Injection of glucose increased plasma insulin and glucose. Neither insulin nor glucose treatment changed the plasma levels of free fatty acids. These data suggest that a limited availability of insulin permits a high rat of ketogenesis and hence induced ketosis in newborn and suckling rats.
Speculation

Developing rats suckled by their dams derive most of their energy from the high fat and low carbohydrate content of milk. The low concentration of insulin in suckling rats not only minimizes utilization of glucose by insulin-dependent tissues but permits a rapid synthesis of ketone bodies that then serve as energy sources for extrahepatic tissues, particularly the brain. Consequently, the energy requirements of suckling rats can be met with a reduced risk of hypoglycemia. Further studies on the effect of insulin on lipolysis, fatty acid oxidation, and ketone synthesis in vitro could add to our understanding of the action of insulin in reversing ketosis of suckling rats.

Ketosis of human infants resembles that of suckling rats in many respects. In both species, plasma levels of ketone bodies are low at birth but increase rapidly after birth and remain high throughout the suckling period $(18,26,27)$. Coincident with these high levels of ketone bodies, plasma concentrations of free fatty acids are elevated during the developing stage in humans and rats $(26,27)$. The elevated fatty acid levels probably stem from the fact that newborns of all mammalian species derive most of their energy 
from fat deposited in adipose tissue (24) or breast milk (3). However, neither the cause nor the function of elevated ketone bodies in newborns has been established. Because controlled experiments are difficult to perform with humans, studies on ketone metabolism in newborn rats should add to our understanding of newborn ketosis in humans.

Studies of ketosis in adult rats have indicated that levels of ketone bodies in plasma are determined by the rate of formation and/or utilization of ketone bodies $(14,32)$. In the brain the activities of enzymes for ketone utilization $(15,18,26)$ appear to increase after birth to a level 3 times higher than found in adult rats. Similarly, the rate of ketone utilization by the brain of suckling rats is 3-4 times higher than that of the adult brain (14) These findings, together with increased activities of ketogenic enzymes (18), suggest increased ketogenesis in the liver as the cause of ketosis in newborn rats. Indeed, an increased capacity for ketone production has been reported in developing rats $(9,17)$.

Hepatic ketogenesis is closely associated with the generation of acetyl-CoA (Ac-CoA) (19) and fatty acid oxidation (2), which is influenced by nutritional status and hormones (21). In fasted, fat-fed, or diabetic adult rats, depletion and impaired utilization of glucose increases fatty acid oxidation and hence the production of Ac-CoA $(21,22)$. Insulin not only increases glucose utilization (29) but inhibits lipolysis $(23,31)$, which in turn depresses fatty acid oxidation. The importance of insulin in regulating lipid metabolism and ketogenesis is therefore apparent. Foster (11) has shown that ketosis of fasting in adult rats disappeared immediately after insulin administration, indicating that insulin may suppress ketone formation. Meier et al. (22) showed that in plasma of alloxan diabetic rats levels of ketone bodies and free fatty acids rose whereas insulin decreased. This further suggests an inverse relationship between the concentration of ketone bodies and insulin.

Reported here are studies of the function of insulin in ketosis of suckling rats. The results show that ketosis of developing rats is closely related to the low level of insulin in plasma. Administration of insulin or glucose to suckling rats caused insulin concentrations to increase, with a consequent decrease in plasma ketone bodies to levels observed at birth.

\section{METHODS AND MATERIALS}

Sprague-Dawley rats obtained from the Laboratory Animal Division of the Mogul Corp., Madison, Wisc., were used throughout the experiments. Pregnant rats were kept individually in stainless steel cages and were fed ad libitum a Purina rat chow containing (per $100 \mathrm{~g}$ ) $23 \%$ protein, $57 \%$ carbohydrate, and $4.5 \%$ fat. Newborn rats were obtained by natural delivery and suckled by their mothers after birth until used. For studies of metabolic changes at birth and before the first postnatal suckling, fet uses of 22 days of gestation were obtained by cesarean section. Adult rats weighing $150-250 \mathrm{~g}$ and fed ad libitum or fasted for $48 \mathrm{hr}$ were used as a reference group.

Blood was collected with heparinized tubes from the jugular vein of newborn and suckling rats and from the tail vein of adult rats. Because of the small size of rat pups, blood samples from two to four pups were pooled to obtain a sufficient quantity of plasma for biochemical analyses. $\beta$-Hydroxybutyrate and acetoacetate were determined enzymatically by the method of McGarry and Foster (20). Glucose was measured by the glucose oxidase method using glucostat (34); free fatty acids by the procedure of Ko and Royer (16); and insulin by the method of Hales and Randle (13) using the anti-guniea pig insulin serum provided in a commercial assay kit (35).

For in vivo studies, insulin $(0.125 \mathrm{mU} / \mathrm{g}$ body weight $)$ was given intramuscularly, and glucose ( $1.75 \mathrm{mg} / \mathrm{g}$ body weight $)$ intraperitoneally. After administration of insulin and glucose suckling rats were allowed to stay with their dams for 20-30 min before blood collection.

For studies of ketogenesis in vitro, portions of rat liver were placed in cold saline $(0.9 \% \mathrm{NaCl})$ immediately after the animals were killed. Liver homogenates $(20 \% \mathrm{w} / \mathrm{v})$ were prepared in $\mathrm{Ca}^{++}$-free Krebs-Ringer phosphate buffer $(\mathrm{pH} 7.4)$ with glass homogenizers equipped with a Teflon pestle at $4^{\circ}$. Of the liver homogenates, $0.8 \mathrm{ml}$ was incubated in $1.2 \mathrm{ml}$ of $\mathrm{Ca}^{++}$-free Krebs-Ringer phosphate buffer $\left(\mathrm{pH} \mathrm{7.4)}\right.$ at $37^{\circ}$ for $10 \mathrm{~min}$ in a metabolic shaker ( 90 strokes $/ \mathrm{min}$ ). At the end of incubation the medium was transferred to a centrifuge tube containing $0.25 \mathrm{ml}$ $40 \%(\mathrm{w} / \mathrm{v})$ perchloric acid. The tube was placed in cold for $20 \mathrm{~min}$ and then centrifuged at $1,500 \times g$ for $10 \mathrm{~min}$. The resulting supernatant was neutralized with $40 \% \mathrm{KOH}$ and centrifuged in the same manner. The neutralized supernatant was used for assaying $\beta$-hydroxybutyrate and acetoacetate. The net synthesis of ketone bodies was calculated by subtracting the initial concentration of ketones from that obtained after 10 -min incubation. The rate of ketogenesis was expressed as micromoles of ketone produced per $g$ wet liver per $10 \mathrm{~min}$.

All chemicals were reagent grade. Insulin was obtained from Eli Lilly Pharmaceutical Co., Indianapolis, Ind.

\section{RESULTS}

We first measured concentrations of plasma metabolites and insulin during the entire suckling period to determine whether changes in these levels are related to the development of newborn ketosis. The average plasma concentration of total ketone bodies (a sum of $\beta$-hydroxybutyrate and acetoacetate) measured at birth and before the first postnatal feeding was $0.414 \pm 0.037 \mu \mathrm{mol} / \mathrm{ml}$. Within $24 \mathrm{hr}$ after birth the level of ketones had increased to 4 times its initial value. A similar rise in total plasma ketones occurred in aduit rats fasted for $48 \mathrm{hr}$. In the suckling rats the 3- to 4-fold increase in plasma ketones was maintained during the first 5 days of life but started to decline thereafter. However, the levels of ketone bodies during the suckling period between days 10 and 20 were still twice as high as values obtained at birth. The calculated ratio of the two ketone bodies (data not shown) indicated that $\beta$-hydroxybutyrate increased more rapidly than acetoacetate at all time points throughout the suckling period. Reasons for the drop of ketone bodies during the second half of the postnatal period are not clear. The increased activities of ketone-utilizing enzymes (15, $18,26)$ during the suckling period appear to suggest that a high rate of ketone oxidation (14) during this corresponding stage may in part account for the decrease plasma level of ketone bodies. It is also possible that increased urinary clearance of ketones during the developing stage could result in low levels of plasma ketone bodies.

Hyperketonemia observed in adult rats under various nutritional conditions, e.g., starvation or fat feeding, is always accompanied by an increased influx of fatty acids to the liver (25). Accordingly, plasma levels of free fatty acids were measured in suckling rats (Fig. $1 B$ ). Newborn rats at birth had a low level of free fatty acids, $0.077 \pm 0.008 \mu \mathrm{Eq} / \mathrm{ml}$, as compared with a value of $0.266 \pm 0.064$ $\mu \mathrm{Eq} / \mathrm{ml}$ in fed adult rats $(P<0.05)$. The levels of free fatty acids increased rapidly to a maximum value on day $l$ and remained at 9to 12-fold increased levels for 10 days. These levels remained high but appeared to decline gradually after the 15th day of life.

Fatty acids and glucose have complementary roles in furnishing energy for adult rats (28). The depletion of glucose is known to increase the release and utilization of fatty acids (28). Thus, the relationship of plasma ketone bodies to glucose availability was examined. Newborn rats at birth had plasma glucose of $99 \pm 3$ $\mathrm{mg} / 100 \mathrm{ml}$, which decreased to $84 \pm 4 \mathrm{mg} / 100 \mathrm{ml}$ on the first day of life (Fig. 1C). The plasma levels of glucose returned to the initial value on the third day of life and increased gradually thereafter. At weaning, when plasma ketones remained high (Fig. $1 A$ ), glucose had reached the level for fed adult rats $(149 \pm 4 \mathrm{mg} / 100 \mathrm{ml})$.

Insulin suppresses ketosis in fasted and diabetic adult rats (11, 22). Reversal of ketosis by insulin could possible result from either stimulation of glucose utilization or inhibition on ketone production. To determine the role of insulin in newborn ketosis we measured plasma immunoreactive insulin of rats throughout the suckling period. As shown in Fig. $1 D$, plasma insulin of newborn 

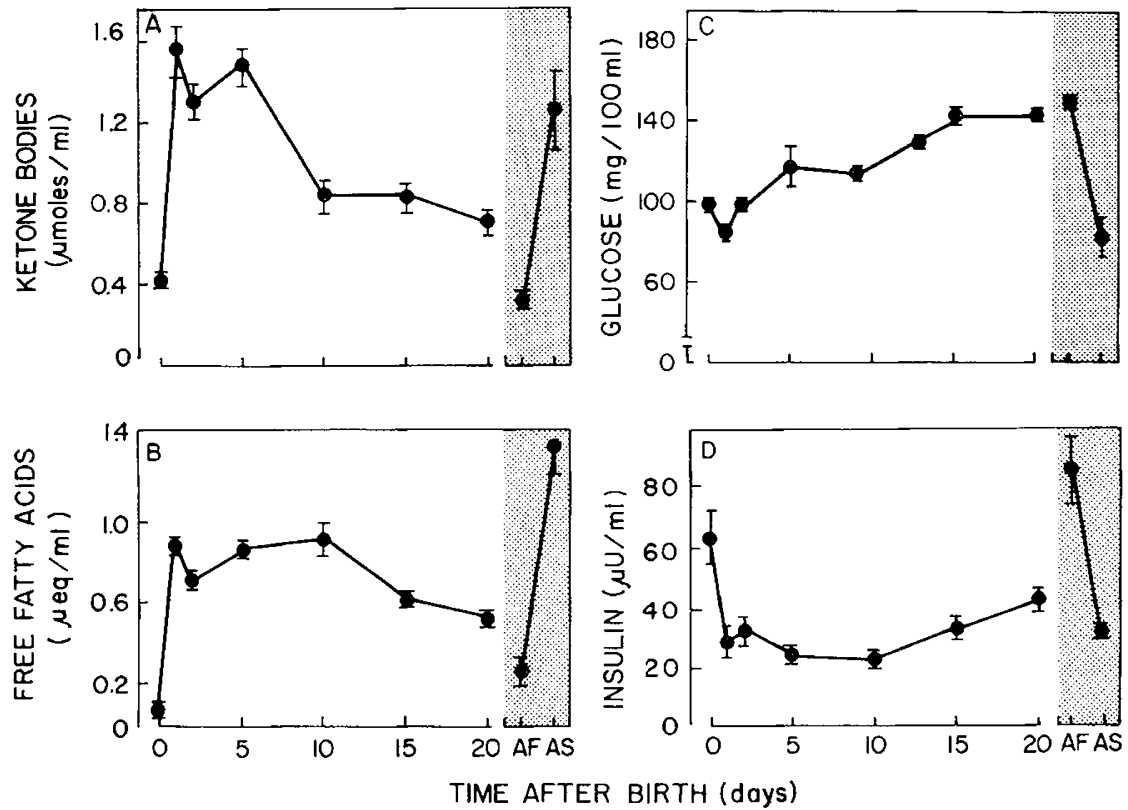

Fig. 1. Interrelation of plasma concentrations of ketone bodies, free fatty acids, glucose, and insulin in neonatal rats. Each point represents a mean value \pm SEM for 6-20 samples. Each sample consisted of two to four pups depending on size of animals. Pups used in all ages except at birth were suckled by their dams until experiments began. Points depicted in shaded area were obtained from adult rats fed ad libitum $(A F)$ or starved for $48 \mathrm{hr}(A S)$. Ketone bodies represent a sum of $\beta$-hydroxybutyrate and acetoacetate.

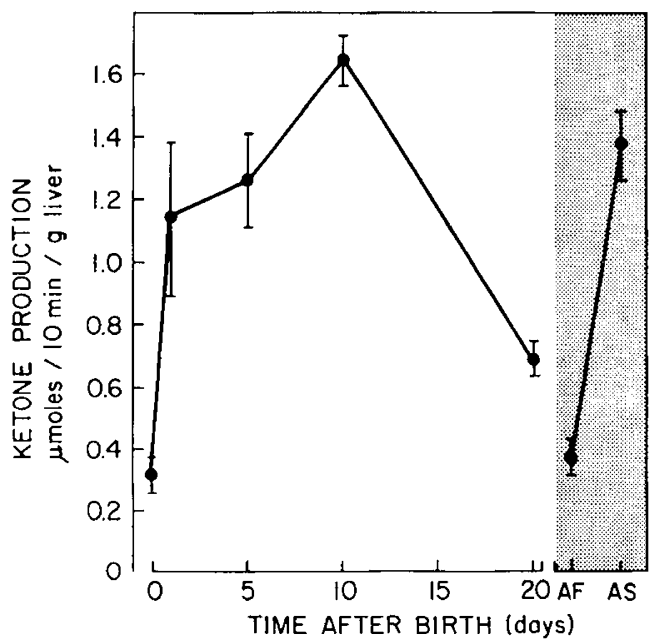

Fig. 2. Synthesis of ketone bodies in liver homogenates of neonatal rats. Liver homogenate $(0.16 \mathrm{~g}$ liver $)$ was incubated in $2.0 \mathrm{ml}$ of $\mathrm{Ca}^{++}$-free Kreber-Ringer phosphate buffer ( $\mathrm{pH} 7.4$ ) containing $3 \%$ of bovine serum albumin at $37^{\circ}$. Each point represents a mean value \pm SEM for six pups. Pups used at all ages except at birth were suckled by their dams until killed. Points depicted in shaded area represent mean values \pm SEM for five adult rats fed ad libitum $(A F)$ or starved for $48 \mathrm{hr}(A S)$. Ketone production is a sum of $\beta$-hydroxybutyrate and acetoacetate synthesized.

rats at birth $(62 \pm 8 \mu \mathrm{U} / \mathrm{ml})$ was comparable with that of fed adult rats $(85 \pm 10 \mu \mathrm{U} / \mathrm{ml})$. The levels decreased to $28 \pm 5 \mu \mathrm{U} / \mathrm{ml}$ on the first day of life and stayed low throughout the suckling period despite a tendency to increase at the time close to weaning. These data indicate a reciprocal relationship between plasma ketone bodies and insulin in developing rats.

Similarly, the capacities for ketone production in liver homogenates of suckling rats were inversely related to the levels of plasma insulin (Figs. $I D$ and 2). The rate of synthesis was low at birth while plasma insulin was high. When plasma insulin decreased, the hepatic synthetic capacities were stimulated by 4 - to 5 -fold during the first 10 days of life. The increased rates of the synthesis were similar to those in adult rats fasted for $48 \mathrm{hr}$. The synthesis of

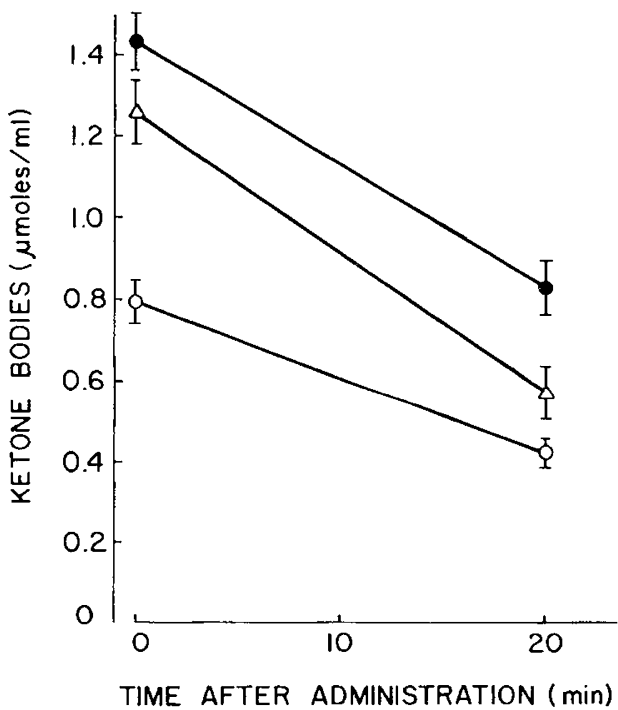

Fig. 3. Effect of insulin administration on plasma concentrations of ketone bodies in suckling rats. Insulin $(0.125 \mathrm{mU} / \mathrm{g}$ body weight) was administered intramuscularly to l-day-old $(\bullet), 5$-day-old $(\Delta)$, and 10-dayold $(O)$ rats. At 20 min after administration of insulin blood samples were obtained. Each point represents a mean \pm SEM for four pups. Ketone bodies represent a sum of $\beta$-hydroxybutyrate and acetoacetate.

ketone bodies started decreasing on day 10 whereas insulin appeared to increase.

The association of elevated ketone bodies with low levels of insulin observed in developing rats suggests that ketosis is related with insulin insufficiency and may be reversed by elevating insulin concentration. To test this possibility we conducted experiments in that suckling rats were treated with insulin and glucose, which is known to stimulate insulin secretion (6). Intramuscular injection of insulin in a dose of $1 \mathrm{mU} / \mathrm{g}$ body weight had no effect on plasma ketone bodies but resulted in decreased glucose levels in 1- to 10-day-old rats (Table 1). However, in a lower dose $(0.125 \mathrm{mU} / \mathrm{g}$ body weight) insulin was effective in suppressing plasma ketone concentration (Fig. 3). Plasma levels of ketone bodies in 1-day-old 
rats decreased $42 \%$ at 20 min after insulin administration, whereas in 5- or 10-day-old rats the ketone levels were reduced to $0.572 \pm$ 0.069 and $0.427 \pm 0.034 \mu \mathrm{mol} / \mathrm{ml}$, that were comparable with the level $(0.414 \pm 0.037 \mu \mathrm{mol} / \mathrm{ml}$; Fig. $1 A)$ observed at birth. Similarly, glucose given intraperitoneally in a dose of $1.75 \mathrm{mg} / \mathrm{g}$ body weight suppressed plasma levels of ketone bodies to $60 \%$ of the untreated control in 1-day-old rats. In older rats, 5 and 10 days old, glucose administration also decreased plasma ketone bodies to the level seen at birth. The effects of insulin and glucose administration on metabolism of lipid and glucose were investigated further by using the same types of experiments. Administration of insulin $(0.125 \mathrm{mU} / \mathrm{g}$ body weight $)$ and glucose $(1.75 \mathrm{mg} / \mathrm{g}$ body weight) again significantly suppressed plasma ketone bodies in suckling rats with a greater depression observed in 5-day-old than 1-day-old rats (Table 2). Administration of the low dose of insulin to 1 - and 5-day-old pups increased plasma levels of insulin to 2- and 1.8-fold over untreated controls but failed to decrease plasma glucose. Glucose administration, on the other hand increased insulin to 2.5- to 2.8-fold and glucose to 2.1- to 2.9-fold over untreated controls (Fig. 4). Neither insulin nor glucose treatment changed the plasma level of free fatty acids.

Table 1. Effect of high dose of insulin on plasma levels of ketone bodies and glucose in suckling rats ${ }^{1}$

\begin{tabular}{lcc}
\hline Treatment & $\begin{array}{c}\text { Ketone } \\
\text { bodies, } \\
\mu \mathrm{mol} / \mathrm{ml}\end{array}$ & $\begin{array}{c}\text { Glucose, } \\
\mathrm{mg} / 100 \mathrm{ml}\end{array}$ \\
\hline $\begin{array}{l}\text { 1-day-old rats } \\
\text { Untreated }\end{array}$ & $1.323 \pm 0.083^{3}$ & $89 \pm 3$ \\
Insulin & $1.435 \pm 0.088$ & $68 \pm 5^{4}$ \\
$\begin{array}{l}\text { 5-day-old rats } \\
\text { Untreated }\end{array}$ & $1.160 \pm 0.081$ & $131 \pm 9$ \\
Insulin & $1.222 \pm 0.109$ & $83 \pm 12^{4}$ \\
10-day-old rats & $0.774 \pm 0.135$ & $142 \pm 3$ \\
Untreated & $0.535 \pm 0.050$ & $104 \pm 13^{4}$ \\
Insulin &
\end{tabular}

${ }^{1}$ Insulin $(1 \mathrm{mU} / \mathrm{g}$ body weight) was administered intramuscularly to suckling rats $20 \mathrm{~min}$ before the collection of blood samples.

${ }^{2}$ Ketone bodies represent a sum of $\beta$-hydroxybutyrate and acetoacetate.

${ }^{3}$ Values represent means \pm SEM for four pups.

${ }^{4}$ Indicate statistically significant difference from the untreated pups within the same age group at $P<0.05$.

\section{DISCUSSION}

In this study low levels of plasma ketone bodies at birth increased rapidly after the beginning of postnatal feeding. The elevated ketone levels of suckling rats were accompanied by high free fatty acids, low insulin, and gradually increased glucose to the level seen in adult fed rats (Fig. 1). Although similar changes in plasma concentrations of ketones, free fatty acids and glucose (18) and insulin (7) in suckling rats have been reported, their relationship to ketosis is not clear.

Our results demonstrtate a reciprocal relationship between the plasma concentration of ketone bodies and availability of insulin in developing rats. Ketosis of newborn rats did not appear until plasma insulin had dropped from the level seen in fed adult rats to a low level which was comparable with that of adult rats fasted for

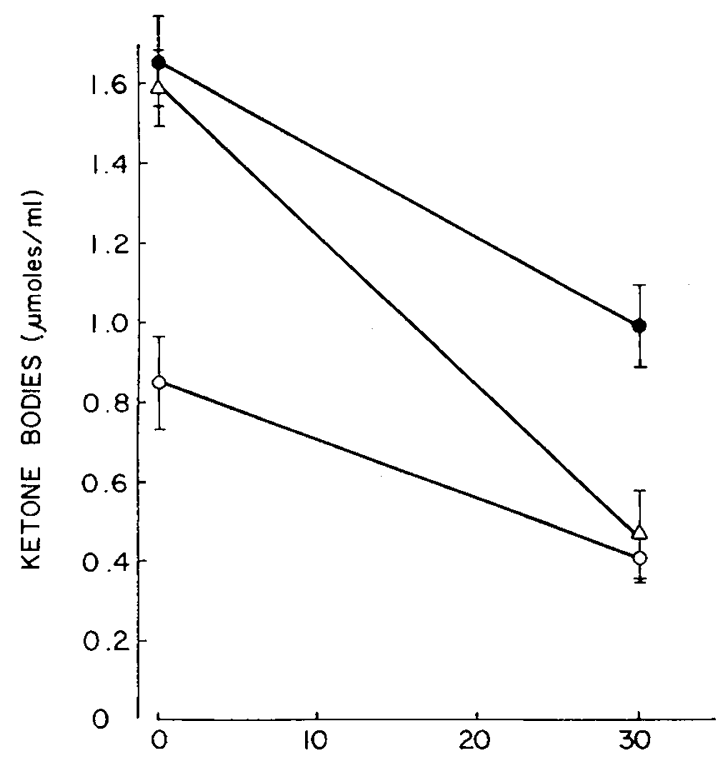

TIME AFTER ADMINISTRATION ( $\mathrm{min}$ )

Fig. 4. Effect of glucose administration on plasma concentrations of ketone bodies in suckling rats. Glucose $(1.75 \mathrm{mg} / \mathrm{g}$ body weight) was administered intraperitoneally to 1-day-old $(\bullet), 5$-day-old $(\Delta)$, and 10-day-old $(O)$ rats. At $30 \mathrm{~min}$ after administration of glucose blood samples were obtained. Each point represents a mean \pm SEM for four to six pups. Ketone bodies represent a sum of $\beta$-hydroxybutyrate and acetoacetate.

Table 2. Comparative changes in plasma levels of ketone bodies, insulin, glucose, and free fatty acids in suckling rats treated with insulin and glucose ${ }^{1}$

\begin{tabular}{|c|c|c|c|c|}
\hline Treatment & $\begin{array}{c}\text { Ketone bodies, }{ }^{2} \\
\mu \mathrm{mol} / \mathrm{ml}\end{array}$ & $\begin{array}{l}\text { Insulin, } \\
\mu \mathrm{U} / \mathrm{ml}\end{array}$ & $\begin{array}{l}\text { Glucose, } \\
\mathrm{mg} / 100 \mathrm{ml}\end{array}$ & $\begin{array}{c}\text { Free fatty acids, } \\
\qquad \mu \mathrm{Eq} / \mathrm{ml}\end{array}$ \\
\hline \multicolumn{5}{|l|}{ 1-day-old rats } \\
\hline Insulin & $1.169 \pm 0.063(8)^{4}$ & $56 \pm 5(8)^{4}$ & $72 \pm 2(8)$ & $1.423 \pm 0.228$ \\
\hline Glucose & $1.142 \pm 0.109(8)^{4}$ & $70 \pm 9(8)^{4}$ & $212 \pm 10(8)^{5}$ & $1.310 \pm 0.500(4)$ \\
\hline \multicolumn{5}{|l|}{ 5-day-old rats } \\
\hline Glucose & $0.453 \pm 0.033(6)^{5}$ & $87 \pm 3(5)^{5}$ & $235 \pm 7(6)^{5}$ & $0.784 \pm 0.098$ \\
\hline
\end{tabular}

${ }^{1}$ Insulin $(0.125 \mathrm{mU} / \mathrm{g}$ body weight, im) and glucose $(1.75 \mathrm{mg} / \mathrm{g}$ body weight, ip) was administered 20 and 30 min, respectively, before the collection of blood samples.

${ }^{2}$ Ketone bodies represent a sum of $\beta$-hydroxybutyrate and acetoacetate.

${ }^{3}$ Values represent means \pm SEM for number of samples indicated in parentheses. Each sample consisted of combined blood obtained from two to four pups.

${ }^{4}$ Indicates statistically significant difference from the untreated pups within the same age group at $P<0.01$.

${ }^{5}$ As Footnote $4, P<0.001$. 
$48 \mathrm{hr}$ (Fig. $1 A$ and $D$ ). Ketosis persisted throughout the suckling period while insulin levels remained low. The rate of ketone synthesis $(9,17)$ and activities of ketogenic enzymes (18) in the liver have been shown to be higher in suckling rats than in adult rats. Because utilization of ketone bodies by extrahepatic tissues, e.g., brain, is stimulated in suckling rats (14), newborn ketosis is most likely the result of increased synthesis of ketone bodies. In accord with these findings, we observed that elevated concentrations of plasma ketone bodies in developing rats were closely related to increased capacities for ketone synthesis in the liver (Figs. $1 A$ and 2). Our data therefore suggest that a limited availability of insulin permits a high rate of ketone production during the suckling period. This contention is substantiated by a reciprocal relationship between hepatic ketogenesis and plasma insulin levels (Figs. $1 D$ and 2). Hepatic ketogenesis was low at birth when newborn rats had a high level of insulin similar to that in fed adult rats. After insulin had dropped to low levels, ketone synthesis increased throughout the suckling period. Conversely, when plasma levels of insulin were increased by administration of either insulin or glucose, elevated ketone levels were suppressed to the same level seen at birth. Since insulin and glucose each stimulates glucose utilization (29) but inhibits lipolysis $(23,31)$, we considered that reversal of ketosis by insulin or glucose could be secondary to increased glucose utilization and decreased lipid mobilization. This seems unlikely, however, because the low dose of insulin $(0.125 \mathrm{mU} / \mathrm{g}$ body weight $)$ failed to decrease glucose and free fatty acids while it was effective in lowering plasma levels of ketone bodies (Table 2). On the other hand, when a higher dose of insulin ( $1.0 \mathrm{mU} / \mathrm{g}$ body weight) was given to suckling rats, the plasma ketone levels remained unchanged, whereas glucose was significantly reduced (Table 1). These data therefore suggest that the concentration of insulin required for depression of plasma ketones is lower than for glucose metabolism and for lipolysis. The mechanism by which insulin reverses ketosis of developing rats is not clear from the present studies. In adult rats, insulin has been shown to inhibit hepatic ketogenesis $(5,11)$ and to stimulate ketone utilization by extrahepatic tissues (4). Whether insulin has similar effects on synthesis and utilization of ketone bodies, and hence suppresses plasma ketone concentration, is presently under investigation.

Persistently low levels of plasma insulin were observed at various stages of development when plasma glucose increased gradually to the level of fed adult rats (Fig. 1, $C$ and $D$ ). The reason for the dissociation of plasma insulin from glucose is obscure. A low level of insulin has also been reported in human (30) and rat (7) neonates. Recently Asplund et al. (1) and Blazquez et al. (6) have reported that insulin release from isolated pancreatic islets of suckling rats did not respond to glucose unless its concentration was increased to $300 \mathrm{mg} / 100 \mathrm{ml}$ in the incubation medium. Blazquez learned from in vivo studies that response of insulin release to glucose was not fully developed until weaning (6). Our results obtained in intact animals also indicate that secretion of insulin is dependent on glucose concentration and maturity of the animal. Although plasma insulin levels were not altered by endogenously increased glucose concentrations ranging from 84 to $142 \mathrm{mg} / 100 \mathrm{mi}$ (Fig. 1C), they did increase significantly after glucose administration which raised plasma glucose to $210 \mathrm{mg} / 100$ $\mathrm{ml}$ or above (Table 2). Furthermore, plasma insulin of suckling rats appears to increase at the time close to weaning (Fig. $1 D$ ). In contrast to the suckling stage, newborn rats at birth had a high level of plasma insulin (Fig. 1D). The earlier study has shown that in the last days of gestation fetuses released more insulin from the pancreas than adult fed rats (7). Since the placenta is not permeable to insulin, the high concentration of plasma insulin observed at birth is likely of fetal origin (7).

The concentration of free fatty acids in plasma of suckling rats appears to fluctuate depending on the availability of energy sources from endogeneous or dietary fat. The low level of plasma-free fatty acids of new born rats at birth and before the postnatal feeding (Fig. $1 B$ ) could be attributed to a limited lipid reserve (12). As soon as the newborns began feeding on milk, a high fat diet (10), the concentration of free fatty acids increased sharply (Fig. $1 B$ ). Because elevated plasma ketone bodies was accompanied by high levels of free fatty acids, the metabolism of fatty acids could be a prime cause of ketosis in suckling rats (8). However, studies of fasted and diabetic adult rats indicate that the increased influx of fatty acids itself does not necessarily lead to increased ketone production $(22,33)$. In the present studies we demonstrated that although plasma concentrations of free fatty acids remained unchanged and high in rats treated with insulin or glucose, ketone bodies were markedly depressed (Table 2). More importantly, the decrease in plasma-free fatty acids was preceded by suppression of plasma ketone bodies (Fig. 1, $A$ and $B$ ). Thus, our results support the concept that the level of free fatty acids does not regulate ketone synthesis, although an increase in fatty acids is a prerequisite for hyperketonemia $(5,33)$.

\section{SUMMARY}

Temporal changes in plasma concentrations of free fatty acids, glucose, and insulin and their relation to ketosis were studied in newborn and suckling rats. Hyperketonemia of developing rats occurred only after the start of postnatal feeding and persisted throughout the suckling period. The magnitude of rise in plasma ketone bodies of pups during early stages of development was similar to that of adult rats fasted for $48 \mathrm{hr}$. Although plasma ketone bodies and free fatty acids were both elevated during development, the level of free fatty acids did not appear to regulate ketone metabolism. During the first 3 days of life, plasma concentrations of glucose were low whereas ketone bodies had reached a maximum level. Thereafter plasma glucose increased gradually and by the time of weaning, when hyperketonemia was still apparent, glucose increased to the level seen in fed adult rats. Depletion of glucose, therefore, might not be associated with hyperketonemia of suckling rats. A reciprocal relationship between plasma insulin and ketone bodies was demonstrated. Elevated plasma levels of ketone bodies were closely related to low levels of insulin at various stages of development. A similar inverse relationship between plasma insulin concentration and hepatic ketogenesis was observed throughout the suckling period. Administration of insulin or glucose elevated plasma concentration of insulin and consequently suppressed plasma ketone bodies. These data suggest that a limited availability of insulin permits a high rate of ketone synthesis and hence induces hyperketonemia in newborn and suckling rats.

\section{REFERENCES AND NOTES}

1. Asplund, K., Westman, S., and Hellerstrom, C.: Glucose stimulation of insulin secretion from the isolated pancreas of foetal and newborn rats. Diabetologia, 5: 260 (1969),

2. Augenfeld, J., and Fritz, I. B.: Carnitine palmitoyltransferase activity and fatty acid oxidation by livers from fetal and neonatal rats. Canad. J. Biochem., 48 . 288 (1970).

3. Ballard, F. J., and Hanson, R. W.: Changes in lipid synthesis in rat liver during development. Biochem. J., 102: 952 (1967).

4. Beatty, C. H., Peterson, R. D., Bocek, R. M., and West, E. S.: Acetoacetate and glucose uptake by diaphragm and skeletal msucle from control and diabetic rats. J. Biol. Chem., 234: 11 (1959)

5. Bieberdorf, F. A., Chernick, S. S., and Scow, R. W.: Effect of insulin and diabetes on plasma FFA and ketone bodies in the fasting rat. J. Clin. Invest., 49: 1685 (1970).

6. Blazquez, E., Lipshaw, L. A., Blazquez, M., and Foa, P. P.: The synthesis and release of insulin in fetal, nursing and young adult rats: Studies in vivo and in vitro. Pediat. Res., 9: 17 (1975).

7. Blazquez, E., Montoya, E., and Lopez Quijada, C.: Relationship between insulin concentrations in plasma and pancreas of foetal and weanling rats. J. Endocrinol., 48: 553, (1970).

8. Drahota, Z., Hahn, P., and Honova, E.: Acetoacetate formation by livers of young and adult rats. Biol. Neonat., 9: 124 (1966).

9. Drahota, Z., Hahn, P., Kleinzeller, A., and Kostolansska, A.: Acetoacetate formation by liver slices from adult and infant rats. Biochem. J., 93:61 (1964).

10. Dymsza, H. A., Czajka, D. M., and Miller, S. A.: Influence of artificial diet on weight gain and body composition of the neonatal rat. J. Nutr., 84: 100 (1964).

11. Foster, D. W.: Studies in ketosis of fasting. J. Clin. Invest., 46: 1283 (1967).

12. Hahn, P.: Response of brown and white adipose tissue to lipolytic agents in the 
rat during development. Pediat. Res., 5: 126 (1971).

13. Hales, C. N., and Randle, P. J.: Immunoassay of insulin with insulin-antibody precipitate. Biochem. J., 88: 137 (1963).

14. Hawkins, R. A., Williamson, D. H., and Krebs, H. A.: Ketone-body utilization by adult and suckling rat brain in vivo. Biochem. J., 122: 13 (1971)

15. Klee, C. B., and Solkoloff, L.: Changes in $\mathrm{D}(-)-\beta$-hydroxybutyric dehydrogenase activity during brain maturation in the rat. J. Biol. Chem., 242: 3880 (1967).

16. Ko, H., and Royer, M. E.: A submicromolar assay for nonpolar acids in plasma and depot fat. Anal. Biochem., 20: 205 (1967).

17. Lee, L. P. K., and Fritz, I. B.: Hepatic ketogenesis during development. Canad. J. Biochem., 49: 599 (1971).

18. Lockwood, E. A., and Bailey, E.: The course of ketosis and the activity of key enzymes of ketogenesis and ketone-body utilization during development of the postnatal rat. Biochem. J., 124: 249 (1971).

19. McGarry, J. D., and Foster, D. W.: The regulation of ketogenesis from oleic acid and the influence of antiketogenic agents. J. Biol. Chem., 246: 6247 (1971).

20. McGarry, J. D., Guest, M. J., and Foster, D. W.: Ketone body metabolism in the ketosis of starvation and alloxan diabetes. J. Biol. Chem., 245: 4382 (1970).

21. McGarry, J. D., Meier, J. M., and Foster, D. W.: The effects of starvation and refeeding on carbohydrate and lipid metabolism in vivo and in the perfused rat liver. J. Biol. Chem., 248: 270 (1973).

22. Meier, J. M., McGarry, J. D., Faloona, G. R., Unger, R. H., and Foster, D. W.: Studies of the development of diabetic ketosis in the rat. J. Lipid Res., 13: 228 (1972).

23. Miller, E. A., and Allen, D. O.: Hormone-stimulated lipolysis in isolated fat cells from "young" and "old" rats. J. Lipid Res., 14: 331 (1973).

24. Novak, M., Melichar, V., Hahn, P., and Kolodovsky, O.: Release of free fatty acids from adipose tissue obtained from newborn infants. J. Lipid Res., 6: 91 (1965).

25. Ontko, J. A., and Ziversmit, D. B.: Correlation between concentrations of circulating free fatty acids and ketone bodies. Proc. Soc. Exp. Biol. Med., 12I: 319 (1966).

26. Page, M. A., Krebs, H. A., and Williamson, D. H.: Activities of enzymes of ketone-body utilization in brain and other tissues of suckling rats. Biochem. J., 121: 49 (1971).

27. Persson, B., and Gentz, J.: The pattern of blood lipids, glycerol and ketone bodies during the neonatal period, infancy and childhood. Acta Pediat. Scand., 55. 353 (1966).

28. Randle, P. J., Garland, P. B., Hales, C. N., and Newsholme, E. A.: Glucose fatty-acid cycle: Its rate in insulin sensitivity and metabolic disturbance of diabetes mellitus. Lancet, $i$ : 785 (1963).

29. Renold, A. E., Hasting, A. B., Nesbett, F. B., and Ashmore, J.: Studies on carbohydrate metabolism in rat liver slices. IV. Biochemical sequence of events after insulin administration. J. Biol. Chem., 213: 135 (1955).

30. Stimmler, L.., Brazie, J., and O'Brien, D.: Serum insulin levels in the normal newborn infant. J. Paediat., 63: 783 (1963).

31. Vaughan, M.: Effect of hormones on glucose metabolism in adipose tissue. J. Biol. Chem., 236: 2196 (1961).

32. Williamson, D. H., Bates, M. W., Page, M. A., and Krebs, H. A.: Activities of enzymes involved in acetoacetate utilization in adult mammalian tissues. Biochem. J., 121: 41 (1971).

33. Williamson, D. H., Veloss, D., Ellington, E. V., and Krebs, H. A.: Changes in the concentration of hepatic metabolites on administration of dihydroxyacetone or glycerol to starved rats and their relationship to the control ketogenesis. Biochem. J., 114: 575 (1969).

34. Glucostat, Worthington Biochemical Corp., Freehold, N. J

35. Amersham/Searle Corp., Arlington Heights, Ill.

36. This research was supported in part by United States Public Health Service Research Grant No. HD-08568 and by ALSAC.

37. We are indebted to Ms. E. Pell for technical assistance and to Mr. J. Gilbert for his expert assistance in the preparation of the manuscript.

38. Requests for reprints should be addressed to: Y.-Y. Yeh, Ph.D., Laboratory of Nutrition and Metabolism, St. Jude Children's Research Hospital, Memphis, Tenn. 38101 (USA)

39. Accepted for publication November 10, 1975

\title{
A Study of the Renal Handling of Water in Lipoid Nephrosis
}

\author{
AYFER GUR, PEPITA YAP ADEFUIN, NORMAN J. SIEGEL, ${ }^{(28)}$ AND JOHN P. HAYSLETT
}

Department of Pediatrics and Medicine, Yale University School of Medicine, New Haven, Connecticut, USA

\section{Extract}

Children with lipoid nephrosis were studied during clinical relapse and after complete remission. As expected, the calculated serum oncotic pressure was reduced severely from the remission value of $28.6 \pm 0.9 \mathrm{~mm} \mathrm{Hg}$ to $15.4 \pm 1.1(P<0.005)$ during relapse. Although no apparent change in plasma volume was noted using the volume of distribution of labeled human albumin, calculated plasma volume was reduced $13 \pm 8 \%$ during relapse when estimated from changes in hematocrit. After a water load, the ability to excrete water was markedly blunted during relapse. The clearance of solute-free water $\left(\mathrm{C}_{\mathrm{H}_{2} \mathrm{O}}\right)$ was $0.9 \pm 0.8 \mathrm{ml} / \mathrm{min}$ during relapse, compared with $3.6 \pm 0.6 \mathrm{ml} / \mathrm{min}$ during remission $(P<0.005)$. In addition, there was a reduced maximal urinary concentrating ability during relapse in four of the six patients examined. Mean urine osmolality for the group during relapse was $778 \pm 82 \mathrm{mOsm} / \mathrm{kgH}_{2} \mathrm{O}$ and $991 \pm 71$ during remission $(P<\mathbf{0 . 0 5})$.

The demonstrated alteration in nephron function during relapse of nephrotic syndrome could result from either (l) a decrease in the amount of sodium delivered to the ascending limb of the loop of Henle because of increased proximal reabsorption or (2) a change in the intrinsic characteristics for sodium reabsorption in that segment. Although this observation does not prove that proximal reabsorption is increased, it suggests a common underlying mechanism for altered nephron function in all of the major edema-forming conditions.

\section{Speculation}

The finding that $\mathrm{C}_{\mathrm{H}_{2} \mathrm{O}}$ and maximal concentrating ability are reduced during relapse of the nephrotic syndrome suggests that the reabsorption of sodium is increased in the proximal segment of the nephron. This process may explain the refractoriness to diuretic therapy encountered in some patients with nephrotic syndrome despite the presence of a normal glomerular filtration rate.

Previous clinical studies have demonstrated a markedly imparied water diuresis after water loads in both congestive heart 